\title{
The evolution of protein NMR
}

\author{
Iain D. Campbell * \\ Department of Biochemistry, University of Oxford, Oxford, UK
}

\begin{abstract}
Since the first NMR spectrum of a protein was published over 50 years ago, remarkable technical improvements have led to NMR being recognized as a uniquely powerful tool that can give a wide variety of useful information about macromolecules and their interactions. This article gives an overview of NMR studies of proteins. It presents a personal historical perspective, briefly reviews the current status of the field and reflects on possible future directions. Two specific examples, related to multi-domain complexes and membrane-spanning adhesion receptors, are described to illustrate recent applications. Emphasis is placed on how general advances in molecular biology and technology are changing the nature and focus of NMR studies.

Keywords: Nuclear magnetic resonance, proteins, history, magnets, protein-protein interactions, intrinsically disordered proteins, entropy, structure, dynamics, integrin activation, filamin
\end{abstract}

\author{
Abbreviations \\ 1D, $2 \mathrm{D}$ - one-, two-dimensional \\ CPMG - Carr-Purcell-Meiboom-Gill \\ $\mathrm{CD}$ - circular dichroism \\ COSY - correlation spectroscopy \\ $\mathrm{CW}$ - continuous wave \\ EM - electron microscopy \\ EGF - epidermal growth factor \\ FLN - filamin immunoglobulin-like domain \\ HSQC - heteronuclear single quantum correlation spectroscopy \\ IDP - intrinsically disordered protein \\ ITC - isothermal titration calorimetry \\ $\mathrm{NMR}$ - nuclear magnetic resonance \\ NOE - nuclear Overhauser effect \\ NOESY - nuclear Overhauser effect spectroscopy \\ OI - Oxford Instruments \\ OU - Oxford University \\ PRE - paramagnetic relaxation enhancement \\ RAL - Rutherford Appleton Laboratory \\ RDC - residual dipolar coupling \\ SAXS - small angle X-ray scattering
}

\footnotetext{
*Address for correspondence: Department of Biochemistry, University of Oxford, South Parks Rd, Oxford OX1 3QU, UK. E-mail: iain.campbell@bioch.ox.ac.uk.
} 
SPR - surface plasmon resonance

TROSY - transverse relaxation optimized spectroscopy

\section{Introduction}

Since the initial observations of NMR signals by Bloch and Purcell in 1946, the technique and its applications have undergone remarkable evolutionary change. From tentative explorations of possibilities with primitive instrumentation in the early 1950s, NMR has become a useful tool in astonishingly diverse fields. An incomplete list of published books illustrates the range of applications: organic chemistry [44], quantum computing [100], oil surveying [47], food analysis [121], patient imaging [141] and brain function [107]. NMR is also recognized as a valuable tool in studies of biomolecules: in drug discovery [15], tissue pathology [52], metabolites in body fluids [85], nucleic acids [124], carbohydrates [137] and membranes [29]. In this article I will focus on NMR studies of proteins, beginning with an historical perspective, partly personal, followed by a brief analysis of the current status of the field and ending with speculation about likely future directions.

In a living cell, millions of molecules perform a wide range of specific tasks at controlled speeds and some of them assemble to form intricate structures and machines. To understand how this system comes 'alive' we need knowledge of the structures and their transient interactions [31]. Proteins are central players and our ability to produce and manipulate them has progressed enormously in recent decades. We now have information about a 'proteome' of over $32 \times 10^{6}$ proteins (http://www.ncbi.nlm.nih.gov/refseq/) and the coordinates of more than 90,000 proteins and complexes are deposited in the PDB (http://www.rcsb.org/pdb/home/home.do).

We have also seen remarkable advances in the tools available to study biomolecules. The first glimpse of protein structure, in 1958, arose from an extended and difficult X-ray crystallography project [77]. Since then, X-ray diffraction has become a wonderfully informative tool that can often be used by the non-specialist. We now also have a wide range of other powerful biophysical techniques [33]. Superresolution fluorescence microscopy can track single molecules in living cells. Low resolution information about the shape of complexes can be obtained with electron microscopy (EM) and small angle X-ray scattering (SAXS). Other methods can measure important molecular properties; e.g. mass spectrometry, Fourier transform infra-red (FTIR), circular dichroism (CD), surface plasmon resonance (SPR), and isothermal titration calorimetry (ITC).

A goal of this review is to give a flavor of the amazing technical advances that have occurred in NMR in the last 60 years. These advances should, however, be seen in the context of parallel advances in other areas. As the biological information expands and our ability to collect it gets better we have moved from studies of relatively easy protein targets (e.g. lysozyme) to ones that are increasingly challenging and the questions asked have changed. Initial NMR studies of proteins focused on methodological developments that were required to make the technique viable. This was followed by the excitement generated by a new method that could determine structures in solution but, increasingly, there is a shift to the production of information that is unique and complementary to that provided by other tools.

\section{Historical perspective}

I arrived in Oxford in 1967 to work as a post-doc with Rex Richards, an NMR pioneer in the UK who constructed an early NMR spectrometer largely with his own hands, even winding an electromagnet [111]. Connection with Rex, and Oxford were very good for me. I met many NMR pioneers including 
past and future Nobel Prize winners. I learned much from group members [16,27,34] and group associates like Ray Freeman [40] and I observed exciting studies of membranes [92] and tissues [68] that used instruments we had helped construct. Later, the Rex connection brought membership of the Oxford Enzyme Group a collaborative network of scientists, ahead of its time, with an agenda to study enzymes using a wide variety of techniques (http://www.nationalarchives.gov.uk/a2a/records.aspx?cat=161ncuacs $18390 \&$ cid $=0 \# 0$ ).

The first ${ }^{1} \mathrm{H}$ spectrum of a protein, published in 1957, was collected at a frequency of $40 \mathrm{MHz}$ [114]. That poor spectrum clearly demonstrated that instrumentation would have to improve for progress to be made. State-of-the-art in 1967 was a Varian $220 \mathrm{MHz}$ continuous wave (CW) spectrometer. Spectra of various proteins obtained using that instrument [91] showed, among other things, that NMR could distinguish folded and unfolded proteins but, although it was an advance compared to 1957, the spectral quality was still very poor (Fig. 2(A)). Fortunately, there have been spectacular technical improvements in NMR instrumentation since then.

\subsection{Magnets}

Iron magnets are limited to a maximum of about $100 \mathrm{MHz}$ (Fig. 1) (the field strength $/{ }^{1} \mathrm{H}$ frequency conversion factor is $1 \mathrm{Tesla}=42.578 \mathrm{MHz}$ ). It was realized that higher fields could be generated using solenoids of superconducting wire and Rex Richards, well aware of the need for better instrumentation, collaborated with Oxford Instruments (OI) to develop superconducting magnets. When I arrived in 1967 his group had a superconducting $200 \mathrm{MHz}$ magnet made with $\mathrm{Nb} / \mathrm{Zr}$ wire. It had very poor homogeneity and it went resistive at regular intervals, boiling off all the helium cooling liquid. As illustrated in Fig. 1, stronger and stronger magnetic fields have been introduced over the years and there have been parallel improvements in homogeneity and stability [23]. I was closely involved with the introduction of OI magnets operating at 270,470,600, 750 and $950 \mathrm{MHz}$, all firsts in their time. The '470' was not a great success as an NMR magnet because the room temperature bore was too narrow but it represented a breakthrough in technology as it was a hybrid of multi-filamentary $\mathrm{Nb} / \mathrm{Ti}$ wire with a $\mathrm{Nb} / \mathrm{Sn}$ core.

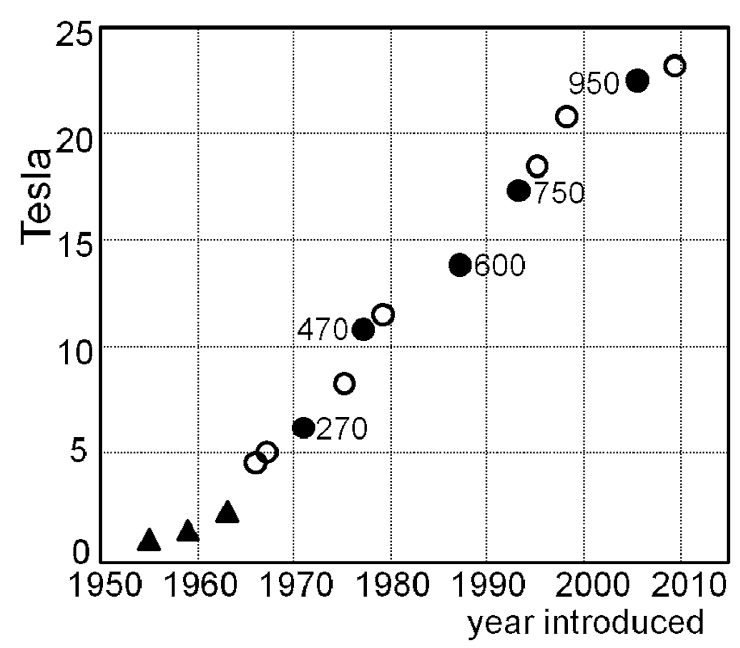

Fig. 1. Increase in available magnetic field strength. A plot showing the years in which various strength magnets were introduced in NMR spectrometers. The triangles and circles represent iron and superconducting magnets respectively. Five of the magnets, constructed by Oxford Instruments and installed at Oxford University, are indicated by filled circles. The corresponding ${ }^{1} \mathrm{H}$ resonant frequencies, in $\mathrm{MHz}$, of these five magnets are shown. 
Because the $\mathrm{Nb} / \mathrm{Sn}$ alloy is brittle it has to be wound as niobium in a tin matrix and baked before it acts as a superconductor. Making such a hybrid magnet with satisfactory superconducting joints between sections made with different kinds of wire was a major challenge and I have minutes of 38 meetings with colleagues from Oxford University (OU), OI and the Rutherford Appleton Lab (RAL), spanning 1975 to 1978; these minutes catalogue many failures but a stable $470 \mathrm{MHz}$ magnet was finally produced and $\mathrm{Nb} / \mathrm{Sn}-\mathrm{Nb} / \mathrm{Ti}$ hybrid magnets still represent the basic technology used for most high-field NMR magnets. Increasing magnet field strength $\left(B_{0}\right)$ brings better sensitivity $\left(\sim B_{0}^{7 / 4} ;[69]\right)$ and better spectral resolution and the increases plotted in Fig. 1 were very important and cost-effective, especially up to around $800 \mathrm{MHz}$.

\subsection{Sensitivity}

Sensitivity (signal-to-noise ratio; $\mathrm{S}: \mathrm{N}$ ) increases with $\mathrm{B}_{0}$, but there are many other factors that contribute to S:N. A variety of upgrades, including quadrature detection, low noise amplifiers, better coupling between probe and sample, and careful matching of the receiver coil magnetic susceptibility, brought great improvements. This is illustrated by quoting the approximate $\mathrm{S}: \mathrm{N}$ ratios achieved on some of our instruments at the time they were introduced, using $0.1 \%$ ethyl benzene as a standard: $90 \mathrm{MHz}-$ 15:1; $270 \mathrm{MHz}-50: 1 ; 600 \mathrm{MHz}-600: 1 ; 750 \mathrm{MHz}-1100: 1 ; 950 \mathrm{MHz}-4000: 1$. Another advance was the introduction of probes where the resistive component of the detection coil is reduced by cooling to low temperatures. This approach was explored by colleagues in 1984 [125] and cold probes are now widely incorporated in commercial instruments, where they can improve sensitivity by a further factor of 3 or so, especially at field strengths up to $800 \mathrm{MHz}$.

\subsection{Fourier transformation and ${ }^{1} H 2 D$ methods}

The advantages brought by Richard Ernst's introduction of pulsed, Fourier transform NMR [58] cannot be overstated. We had explored relaxation times of ${ }^{31} \mathrm{P}$ signals in ATP/manganese complexes on the $200 \mathrm{MHz} \mathrm{Nb} / \mathrm{Zr}$ magnet using paper tape and off-line Fourier transformations [27] but a Bruker-based instrument, installed in the OU Biochemistry Department in 1972 and operating with a $270 \mathrm{MHz} \mathrm{Nb} / \mathrm{Ti}$ magnet was a revelation. As shown by the segment of a lysozyme spectrum in Fig. 2(B) [36], greatly improved spectra could be obtained (Fig. 2(A)) and the data could be manipulated to give resolution enhancement [38]. There was also a realization that pulse sequences could bring about spectral simplifications [37]. (Spectral simplification was also demonstrated in whole cell studies and new information about proteins in cells, metabolism, and membrane transport could be obtained with ${ }^{1} \mathrm{H}$ NMR using spin echo sequences [25,28]; see Fig. A.1.)

The extension of 1D FT methods to $2 \mathrm{D}$ was another landmark. Early $2 \mathrm{D}{ }^{1} \mathrm{H}-{ }^{1} \mathrm{H}$ experiments on proteins gave cross peaks arising from correlations due to spin-coupling (through-bond) [96] and there was a key paper in 1980 showing that through-space networks in proteins could be measured via the nuclear Overhauser effect (NOE) [80]. These important developments made protein structure determination feasible.

\subsection{Spectral assignment}

What makes NMR uniquely powerful as a spectroscopic tool is the ability to resolve and assign multiple resonances to specific groups in a protein. Early assignment efforts included ${ }^{1} \mathrm{H}$ resonances of the four histidines in ribonuclease; these were distinguished by $\mathrm{pH}$ titration, chemical modification and inhibitor binding [93]. As shown in Fig. 2(B), we also managed to make many assignments in lysozyme 


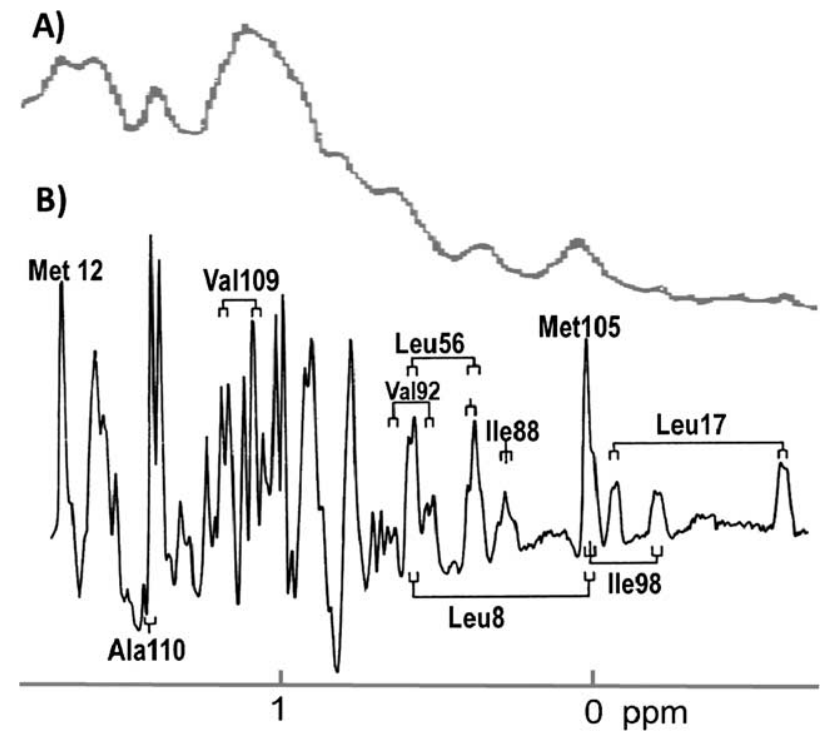

Fig. 2. Spectra of lysozyme. (A) A trace of a small part of a spectrum of lysozyme taken using a $220 \mathrm{MHz} \mathrm{CW}$ instrument (adapted from with permission from [91]). (B) The same region, but obtained using a $270 \mathrm{MHz}$ Fourier transform instrument [36]. The spectrum in (B) was resolution enhanced using 'convolution difference' [38]. It shows some methyl resonance assignments, obtained using lanthanide probes and knowledge of the lysozyme crystal structure.

by adding paramagnetic lanthanide probes to a known binding site in the crystal structure and assigning resonances by correlating distances and angles with the chemical shifts and broadening induced by the added probes. Such methods are not systematic, however, and depend on the specific properties of the protein studied. Methods that could relate resonances to a known protein sequence were required. The Wüthrich lab introduced a systematic method for proteins using 2D ${ }^{1} \mathrm{H}$ spectra [144,145]. Amino acid types were first identified by exploiting through-bond correlations (e.g. COSY), followed by throughspace experiments (NOESY) to identify amino-acid neighbors. As will be discussed below, this ${ }^{1} \mathrm{H}$-only strategy was later extended by the introduction of isotope labels into proteins.

\subsection{Protein structure determination}

An early dream was that NMR could be used to determine structure in solution and be an alternative to crystallography. One such dreamer was Bob Williams in Oxford. He went some way to develop structure determination methods using the shifts and broadening induced by paramagnetic lanthanide probes [11,36] but there were no systematic assignment procedures and too few distance restraints for proteins. Meanwhile in Zürich, systematic assignment and ways of collecting a large number of structural restraints were demonstrated [144]; the main restraints identified were short-range ${ }^{1} \mathrm{H}-{ }^{1} \mathrm{H}$ dipolar interactions (NOEs) between assigned resonances less than $0.5 \mathrm{~nm}$ apart and 3 bond coupling constants ${ }^{3} \mathrm{~J}_{\mathrm{NHH} \alpha}$ [144]. With Havel, Wüthrich also developed a 'distance geometry' method for calculating families of structures consistent with the experimental restraints [66,144]. This led, in 1985, to the first determination of a protein structure in solution using NMR [142].

Inspired by Wüthrich's success, we applied his ${ }^{1} \mathrm{H}$-only methods to solve the structure of epidermal growth factor (EGF) in 1987 [50]. In spite of its functional importance and much prior effort to crystallize it, the structure (Fig. 3) was previously unknown. We did not then know much about protein expression 


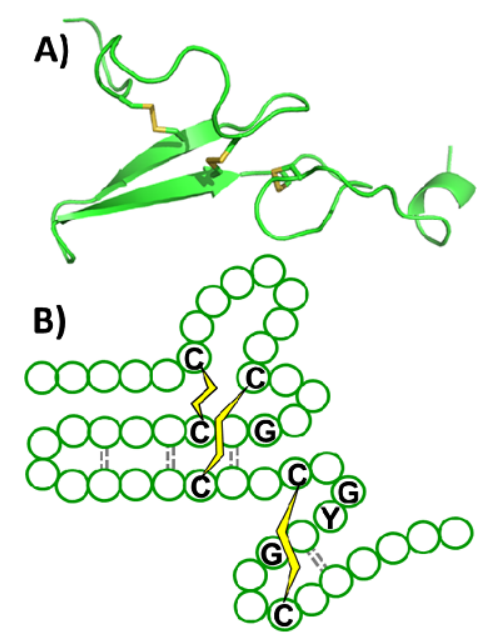

C)

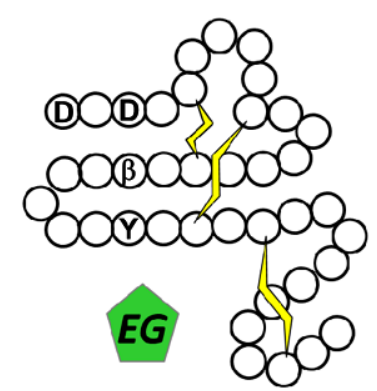

D)

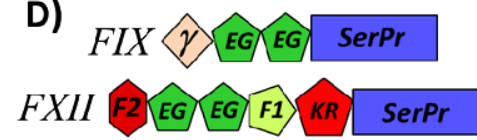

Fig. 3. The EGF module. (A) The NMR structure of human epidermal growth factor (EGF), obtained in 1987 [50]. (B) Representation of the protein topology, showing the position of some conserved amino-acids that have a structural role (adapted with permission from [50]). (C) A representation of an EGF 'module' that appears repeatedly in numerous proteins (see text and [9]). The conserved structural residues identified in (B) remain in $(C)$ but additional residues; e.g. the $\mathrm{D}, \beta$ (hydroxylated $\mathrm{D}$ ) and $\mathrm{Y}$ residues shown here, have a $\mathrm{Ca}^{++}$binding function [65]. (D) EGF modules in two representative modular proteins from the blood clotting system - factors IX and XII; the other modules present are $\gamma=$ Gla; F1 = fibronectin type 1; F2 = fibronectin type $2 ; \mathrm{Kr}=$ kringle; serprot $=$ serine protease.

but a fruitful collaboration with ICI Pharmaceuticals provided the protein and led to the first NMR structure to be solved in the UK [50]. By chance, this period coincided with a growing awareness that proteins are often constructed from a series of autonomously folding modules or domains [9]. In the current SMART database (http://smart.embl.de/smart/do_annotation.pl?DOMAIN=SM00181) the EGF module, a sequence of about forty amino-acids, is identified 45,913 times in 14,726 proteins. The existence of repeating modules means that insight into a large number of interesting biological systems can be gained by solving a consensus module structure, although it does not follow that all modules in a family have similar function. Crystallography was somewhat less competitive than it is now and NMR made a significant impact in module structure determination in the early 1990s. We began a research program focused on the determination of the structure of numerous modules and module pairs by NMR, producing the required proteins ourselves (see e.g. $[8,86,106]$ ). This was an example of a shift from a technologydriven research program to one focused on defining biological structure-function relationships.

\subsection{Multi-dimensional methods and isotope labeling}

The ${ }^{1} \mathrm{H}$-only approach fails for proteins larger than about $12 \mathrm{kDa}$ because of line broadening and spectral overlap. The introduction of the NMR-active isotopes, ${ }^{13} \mathrm{C}$ and ${ }^{15} \mathrm{~N}$, brought two main advantages: it spread the resonances into several dimensions giving better resolution [102] and it gave detectable coupling constants between neighboring amino-acids, leading to more robust spectral assignment [14]. In the early 1980s, we did not have good expression systems but as these improved $[122,123,126]$ and labeling media became cheaper, labeled protein production became increasingly straightforward. In turn, the availability of isotope-labeled proteins led to the development of a powerful array of heteronuclear, multidimensional, edited, and filtered NMR experiments to study them [14,42]. Incorporation of ${ }^{15} \mathrm{~N}$ is especially cheap and convenient and we explored the powerful and popular heteronuclear single quantum correlation spectroscopy (HSQC) experiment for ${ }^{15} \mathrm{~N}$ labeled proteins in Oxford [98] but most of the 
new experiments for double labeled proteins were developed by Ad Bax and colleagues at NIH [14,42]. These sophisticated 'triple resonance' experiments on labeled proteins led to a significant improvement in the spectral information content and this approach is now used whenever possible [42]. As will be discussed below, isotope labeling methods have since been further extended to increase the size of protein that can be studied [112].

\section{The current status of protein NMR}

Studies of proteins by NMR are now astonishingly diverse and numerous; a PubMed search with the words 'protein NMR' currently produces about 68,000 hits. Provided site-specific assignments can be made, the observed variations in NMR experimental parameters, such as chemical shifts, are exquisitely sensitive and informative. Here I will just make a few general points about aspects that indicate the current status (see also [10]).

\subsection{Data collection and structure determination}

We are now in an era with high quality, relatively mature instrumentation. We have high-field magnets with good stability and homogeneity. Modern spectrometers have multi-frequency detection channels, sophisticated pulse controllers, low noise detection systems and relatively user-friendly control software and pulsed field gradients that help greatly with solvent suppression. Some innovation continues, such as improved direct detection methods for relatively insensitive nuclei [17] and faster and more efficient ways of collecting NMR spectra [70,110]. There are also possibilities for enhancing sensitivity with polarization transfer experiments [56,88], but generally the rate of innovation and improvement has slowed. (I am generally addressing solution state NMR methods here; the technology for solid state NMR is more demanding and still advancing [140].)

Since the development of ${ }^{1} \mathrm{H}$-only methods for structure determination in the 1980 s, there have been many improvements and innovations. The incorporation of ${ }^{15} \mathrm{~N}$ and ${ }^{13} \mathrm{C}$ brought the long-term goal of developing robust and effective automation procedures for assignment and structure determination closer but manual intervention is often still required because of experimental imperfections, especially for larger, less well-behaved proteins (frequently the more interesting ones!) [62,63].

Developments of note in structure determination include residual dipolar couplings, stereospecific amino-acid labels, and chemical shift restraints. There are relatively large dipolar interactions between nuclei in NMR that are observed in the solid state but, in solution, these are usually averaged out by fast motion. By partially aligning the protein with suitable media, it is possible to reintroduce a small fraction of these interactions $[13,43]$. These residual dipolar couplings (RDCs) give useful long-range structural information that complements the short-range information given by ${ }^{1} \mathrm{H}-{ }^{1} \mathrm{H}$ NOE restraints [43]. Structural restraints can also be improved by incorporating synthesized amino-acids in proteins in a method called stereo-array isotope labeling (SAIL) but this technique is expensive and is thus unlikely to be widely applied [72]. Chemical shifts in proteins are very sensitive to local structure. Using chemical shifts of assigned resonances $\left({ }^{13} \mathrm{C}_{\alpha},{ }^{13} \mathrm{C}_{\beta},{ }^{13} \mathrm{C}^{\prime},{ }^{15} \mathrm{~N},{ }^{1} \mathrm{H}_{\alpha}\right.$ and $\left.{ }^{1} \mathrm{HN}\right)$ as the only experimental input, a structure determination protocol has been developed that selects protein fragments from the Protein Data Bank in conjunction with Rosetta modelling (https://www.rosettacommons.org/) [118]. This approach has proved to be surprisingly effective in predicting protein structure and the procedures are still being refined [117].

A number of alternative methods for NMR data analysis and structure calculation evolved separately. Efforts to unify and streamline these various approaches are helpful. The websites 
http://www.ccpn.ac.uk/ and http://www.enmr.eu/webportal/ document the various methods and software packages that are available. There is also a useful repository for experimental NMR data on biomolecules (http://www.bmrb.wisc.edu/ref_info/).

The considerable success of NMR structure determination is evidenced by the fact that there are now over 10,000 NMR structures deposited in the PDB (http://www.rcsb.org/pdb/). It is fair to say, however, that NMR structure determination remains relatively slow and laborious compared to crystallography. The structures obtained are less precise, although some of the 'fuzziness' seen in NMR structures arises from genuine uncertainty due to motion. NMR structures are also size limited (see below) and there are special difficulties with symmetric oligomers [59] but, of course, if no crystals can be obtained, crystallography is a non-starter!

\subsection{Protein-ligand interactions}

Computer based molecular docking is increasingly powerful [83] and it can be used in combination with NMR to facilitate drug discovery $[49,105]$ but here I focus mainly on protein-protein interactions (studies of protein-RNA interactions are closely related [51]).

The molecules in a cell interact with each other, temporally and spatially, in well regulated networks. The protein-protein 'interactome' is being unraveled using a variety of methods, including genetics, affinity purification and bioinformatics ([132]; http://thebiogrid.org/). Preliminary identification of interactors by such methods is, however, error prone, so there is a need to obtain detailed kinetic and structural information about the complexes formed. NMR is increasingly recognized as a unique and powerful tool in this area, as it can give not only detailed structural but also kinetic and thermodynamic information about the often weak and short-lived complexes that are formed.

The time scale of protein/ligand equilibria ( $\mathrm{P}+\mathrm{L} \leftrightarrows \mathrm{PL}$ ) is important in NMR. It is said to be 'fast' when one averaged signal is observed for P and PL resonances. Line broadening occurs when the rates are 'intermediate' and separate P and PL signals are observed when the exchange rate is 'slow'. Exchange broadening can cause detection problems when studying complexes but line-shape analysis can give useful kinetic information [35,64,79]. A number of NMR procedures have been developed to characterize protein-ligand interactions, structurally and kinetically [21,99]. A powerful, yet simple, experiment that gives information about dissociation constants and interaction sites, especially when in the fast exchange regime, is to monitor chemical shifts of a labeled protein in HSQC experiments when ligand is added. Further information about this and other experiments that can be used to study protein ligand interactions and the complexes formed can be found in $[21,99]$ and http://www.springerreference.com/docs/html/chapterdbid/309172.html; a specific integrin-related example will also be given below. These various protein-ligand interaction experiments can be complemented by restraint-driven docking programs [74].

Paramagnetic relaxation enhancement (PRE) $[19,39]$ can give information about protein interactions. PRE arises from effects induced by a paramagnetic center introduced into a sample. The protein studied may be intrinsically paramagnetic, otherwise a nitroxide spin label or a chelated lanthanide ion can be introduced [76,103]. PRE can be a sensitive way of detecting transient encounter complexes that form before a ligand reaches a more stable position in a complex [46]. Recent examples include studies of the dynamics and interfaces formed during electron transfer; these give insight into how small proteins such as cytochrome $\mathrm{c}$ transport electrons between larger redox complexes [12].

At the structural level, protein-protein interactions can be considered in two main classes [6], one where two structured domains come together to form a complex and the other where a complex is formed 
from a globular domain and a disordered peptide segment of another protein. A large number of proteins contain disordered regions and these intrinsically disordered proteins (IDPs) are often involved in protein interaction networks. IDPs frequently act as 'hubs' for promiscuous interactions with several different partners [129]. NMR is especially useful for analyzing the numerous weak but specific interactions that occur in IDP/protein complexes and IDPs are difficult to deal with by other methods [71,143].

\subsection{Dynamics}

One area where NMR has unique advantages over other methods is in investigations of molecular movement. Residue-specific information about motion on a wide range of time scales (picosecondshours) can be derived for proteins that are essentially in their physiological state. Some tools for extracting dynamic information are well established; these include relaxation [48,75], H-D exchange [109,138], lineshape analysis [35,64,79] and diffusion measurements using spin echoes (Fig. A.1(A)) [54]. The ${ }^{1} \mathrm{H}-{ }^{15} \mathrm{~N}$ NOE experiment has been widely applied to define fast protein backbone motion $[22,45]$ and molecular dynamics simulations can be used to better interpret the NMR data [119]. Information from analysis of RDCs has been added to the dynamics toolbox more recently [43].

The Carr-Purcell-Meiboom-Gill (CPMG) experiment can give information about dynamics and 'invisible' states [1,34]. A train of $180^{\circ}$ pulses is applied to the sample after a $90^{\circ}$ pulse (see Fig. A.1(A)). The experiment can be relatively insensitive but for some exchange rates between two conformers, the observed relaxation rate varies with the separation $(\tau)$ between the $180^{\circ}$ pulses. The resulting 'relaxation dispersion' curves yield information about $\mu \mathrm{s}-\mathrm{ms}$ timescale dynamics that can, for example, be related to enzyme catalytic activity [20]. The dispersion curves also depend on the chemical shift differences between exchanging conformers [7,101]. This means that the chemical shifts of a low-populated 'invisible' state $(<10 \%)$ can be deduced in favorable cases. These inferred chemical shifts can be used to provide structural information about the invisible state [115].

\subsection{The size limit}

NMR studies are size limited; the linewidths (relaxation rates) increase with molecular weight so that peak resolution and assignment become increasingly difficult. Incorporation of ${ }^{15} \mathrm{~N}$ and ${ }^{13} \mathrm{C}$ into proteins extended the accessible size to $\sim 30 \mathrm{kDa}$ [14] but newer isotopic labeling schemes and pulse sequences have further improved that situation [133]. Relaxation rates can be made more favorable (slower) if the protein of interest is extensively deuterated [87]. Protonated methyl groups incorporated into these deuterated proteins then make useful probes [112] since methyls can be detected with high sensitivity using optimized pulse sequences designed for large systems; e.g. variants of transverse relaxation optimized spectroscopy (TROSY) [131]. These methods make it possible to derive structural information about proteins up to about $100 \mathrm{kDa}$ and information about interactions and dynamics in complexes larger than $500 \mathrm{kDa}$. This approach, which promises to be especially useful for studying interactions and dynamics, has been applied successfully to several large systems, including the proteasome [120].

\section{Two specific examples}

I will now give two recent examples from our own NMR studies. Aspects of these studies have been chosen to illustrate the utility of NMR and the use of multiple, complementary techniques to obtain the required information about the biological system of interest. 


\subsection{Integrin activation, IDPs and entropy}

Integrins are essential adhesion receptors found at the surface of animal cells. They are critical components of structures called focal adhesions that are required for embryonic development, tissue repair and immune defense $[2,30,32,41,116]$. Integrins have membrane-spanning $\alpha$ and $\beta$ subunits, with large ectodomains constructed from various protein modules, a single trans-membrane helix and, usually, a short unstructured cytoplasmic tail (Fig. 4(A)) [2,41]. Integrins exist in equilibrium between bent, low affinity, and upright, high affinity, states and the equilibrium shown in Fig. 4(A) is moved to the high affinity, 'on' state by binding extracellular ligands (L) and/or intracellular talin, a large protein with a head domain consisting of 4 modules (F0-F3) and a rod domain that binds to the actin cytoskeleton $[30,116]$. The activation of integrins by talin has been extensively studied by a variety of in vitro and in cell experiments $[41,73,116,146]$. The current view is that the talin head interacts with the membrane and the $\beta$-tail in a way that promotes separation of the two membrane-spanning helices $[41,73]$. The dynamic assembly of multiple proteins into focal adhesion complexes and the details of the integrin activation process are of considerable interest [30], but here I will focus on the complex formed between the globular talin F3 module and integrin $\beta$ cytoplasmic tails which are flexible IDPs; Fig. 4(B) which shows the structure of a $\beta_{3}$-tail/talin1.F3 complex, determined by NMR.

There are 18 different integrin $\beta$-subunits in humans. The cytoplasmic tail region sequences of three of them are shown in Fig. 4(C); these all bind relatively weakly $\left(\mathrm{K}_{\mathrm{D}}>200 \mu \mathrm{M}\right)$ to the main isoform of talin (talin1). Structure determination of $\beta /$ talin complexes proved to be a very difficult. Our initial attempts to determine an NMR structure of a complex failed because of exchange line broadening and our initial attempts to crystallize a $\beta / \mathrm{F} 3$ complex failed because the complex was too weak to get high enough site occupancy. We knew that the membrane proximal region (see Fig. 4(C)) was functionally important from mutational studies and we had previously determined the structure of peptides corresponding to the NPXY region of the tails (see green line in Fig. 4(C)) [53,60]. Using this information, we solved the problem of exchange broadening by engineering a $\beta$ tail chimera; the membrane proximal region was authentic $\beta_{3}$ but the sequence around the NPXY region was changed to give a tighter complex and induce a slow exchange regime [139]. We also solved the crystallography problem by screening the affinities of various tails for different talin isoforms with HSQC titration experiments on ${ }^{15} \mathrm{~N}$ labeled tails. We found that $\beta_{1 \mathrm{D}}$ bound to a talin2 isoform with a $\mathrm{K}_{\mathrm{D}}$ of $<50 \mu \mathrm{M}$. This relatively tight complex crystallized to yield the structure of an authentic $\beta_{1 \mathrm{D}}$ tail bound to talin2.F2.F3 [5]. Parts of these two structures $\left(\beta_{3} /\right.$ talin1.F3 and $\beta_{1 \mathrm{D}} /$ talin2.F2.F3) are illustrated in Fig. 4(E). The bound $\beta_{1 \mathrm{D}}$ and $\beta_{3}$ tails (red) have similar helical conformations in the region shown; the only charged amino-acid that makes significant contact with talin is a conservative change: $\beta_{3}-\mathrm{R} 734 / \beta_{1 \mathrm{D}}-\mathrm{K} 770$.

The $\beta$-tails are structured in the complexes (Fig. 4(B), (E)) but are very flexible when free in solution [135]. This dynamic property can be seen from the pattern of ${ }^{1} \mathrm{H}-{ }^{15} \mathrm{~N}$ NOEs observed for the three $\beta$-tails shown in Fig. 4(D) [4]. The tails, especially $\beta_{1 \mathrm{D}}$ and $\beta_{1 \mathrm{~A}}$, can thus be classified as IDPs. Figure 4(D) shows that $\beta_{3}$ has a region with a significantly higher ${ }^{1} \mathrm{H}-{ }^{15} \mathrm{~N}$ NOE than the other two $\beta$ sequences and this region coincides with a higher helix propensity prediction for $\beta_{3}$, using AGADIR (http://agadir.crg.es; [95]). A clue to why there is a higher predicted helix propensity for $\beta_{3}$ is given by E732 and R736; it is known that an $(\mathrm{i}+4) \mathrm{E}, \mathrm{K} / \mathrm{R}$, salt bridge promotes helix formation [89]. The E732/R736 pair in $\beta_{3}$ (Fig. 4(E)) is replaced by K768/N772 in $\beta_{1 \mathrm{D}}$ so no salt bridge is expected and indeed this correlates with lower helix propensity prediction and a lower observed ${ }^{1} \mathrm{H}-{ }^{15} \mathrm{~N}$ NOE in $\beta_{1 \mathrm{D}}$. Note that neither E732 nor R736 contact talin F3 in the complex. 


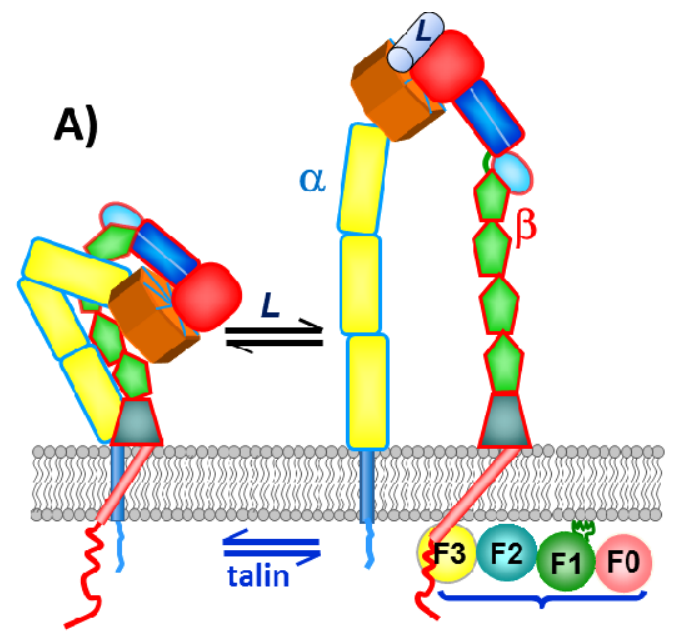

B)

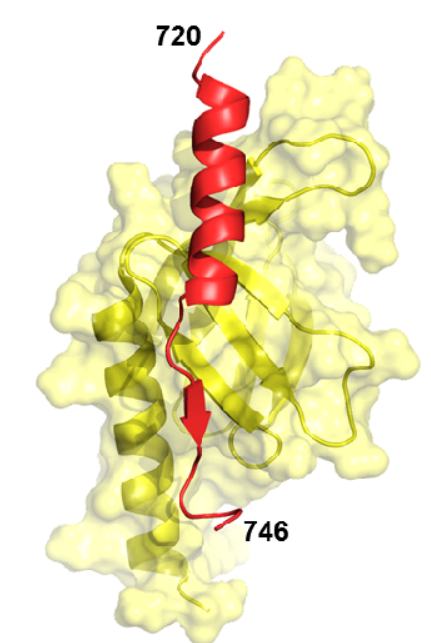

C) $\beta_{1 \mathrm{~A}} 752$ KLLMIIHDRREFAKFEKEKMNAKWDTGENPIYKSAVTTVVNPKYEGK 789

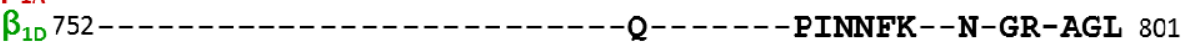
$\boldsymbol{\beta}_{\mathbf{3}} 716$ KLLITIHDRKEFAKFEEERARAKWDTANNPLYKEATSTETNITYRGT 762

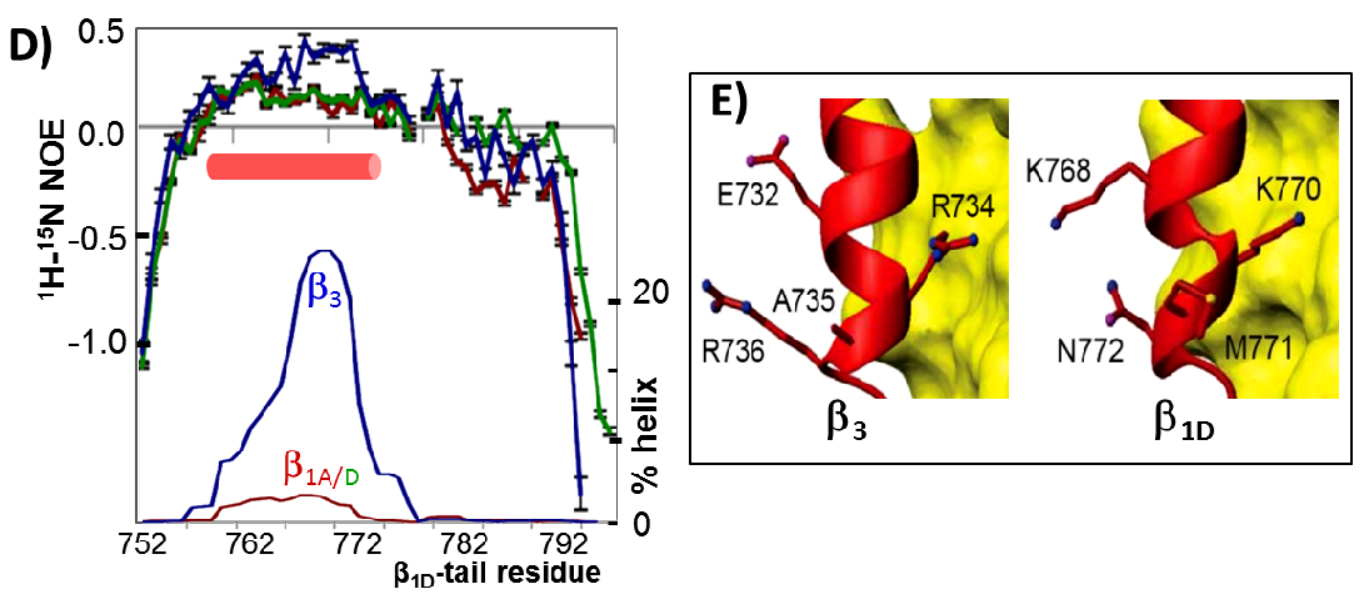

Fig. 4. Integrin activation via cytoplasmic $\beta$-tails. (A) Integrins are large membrane-spanning $\alpha \beta$ heterodimers that can exist in 'on' and 'off' states. The 'on' state can be promoted both by extracellular ligands (L) and by binding of the intracellular protein talin to the cytoplasmic tail of the integrin $\beta$-subunit. The head domain of talin, consisting of 4 modules (F0-F3), is shown bound to the membrane and the $\beta$-tail in the 'on' state [2]. (B) The NMR structure of a complex formed between a $\beta_{3}$ tail chimeric peptide and the talin1 F3 module (PDB entry: 2H7E); residues 722-736 ( $\beta_{3}$-numbering) form a well-defined $\alpha$ helix in the complex. (C) The sequences of three of the 18 different $\beta$ tail sequences that are found in human integrins. The red line below the $\beta_{3}$ sequence indicates a membrane proximal region that forms a helix in the complex while the green line indicates the region around the first NPXY motif. (D) The upper plots show the ${ }^{1} \mathrm{H}-{ }^{15} \mathrm{~N}$ NOEs for the three $\beta$-tails $\left(\beta_{3}-\right.$ blue, $\beta_{1 \mathrm{~A}}-$ red, $\beta_{1 \mathrm{D}}-$ green) in their unbound state; the red cylinder indicates the membrane proximal region that forms a helix on binding; the lower plots show the predicted residue-level $\alpha$-helix propensity of the three sequences, using the program AGADIR (http://agadir.crg.es). (E) Segments of the talin1.F3- $\beta_{3}$ complex (left), determined by NMR (PDB: 2H7E) and the talin2.F2.F3- $\beta_{1 \mathrm{D}}$ complex (right), determined by crystallography (PDB: 3G9W). Panels (D) and (E) are adapted, with permission, from [4].

When IDPs bind to a protein and form a structured complex there is expected to be an associated entropic cost $[136,143]$. We hypothesized that the helical propensity, promoted by the E732/R736 salt bridge, would reduce the entropic cost of $\beta_{3}$ binding to talin F3. To test this hypothesis, a number of $\beta_{3}$ 
mutants were made and their affinities were measured by HSQC titrations. Here we just quote the result for the substitution E732R; this reduced the affinity by more than a factor of two and, as expected, it also lowered the predicted helical propensity and the observed ${ }^{1} \mathrm{H}-{ }^{15} \mathrm{~N}$ NOE [4]. In the same paper, our understanding of a range of complexes formed between peptides and talin F3, as well as their dynamic properties, allowed us to design a $\beta$-tail peptide that had $\sim 1000$ fold higher affinity than wild type for talin F3 [4]. These studies clearly demonstrated that it is not only contact residues that define the affinity of a complex, the dynamic properties of the ligand before it binds are also important.

This study of IDPs and affinity [4] was one of several papers from our lab [2,30,41] that addressed integrin activation, focal adhesion formation and regulatory effects, such as tail phosphorylation [3]. Among other things, these studies showed that fine tuning of affinity is important for function; some integrins have to be switched completely 'off' until an appropriate time (e.g. in blood clotting) while other integrins (e.g. those involved in tissue formation) are often 'on' for most of their lifetime. In other cases, such as in migrating cells, integrins have to be switched readily between 'on' and 'off' states so fast off-rates are required. Numerous techniques, other than NMR, were used in these studies; these included fluorescence activated cell sorting, ITC, mutagenesis, crystallography and molecular dynamics simulations. NMR was, however, a key tool for measuring interactions, structure and dynamics $[2,41$, $73,134,146]$.

\subsection{Filamin module assembly, binding and dynamics}

Filamins are large actin-binding proteins that participate in a wide range of cell functions, including cell migration and membrane protein localization [97]. As well as actin, filamins bind to various other proteins, including integrins, membrane channels and transcription factors. A filamin chain is composed of an N-terminal actin-binding domain and 24 immunoglobulin-like modules (FLN). Two such chains form tail-to-tail dimers via the C-terminal FLN24 (see Fig. 5(A)). Many of the interactions of filamin with other proteins can be mapped to the FLN16-21 region and several of these modules have been characterized in complex with their peptide ligands; e.g. we showed how the FLN21 module binds to integrin $\beta$-tails, and to a protein called migfilin [78,81] (Fig. 5(A)). An initial expectation was that multiple FLN modules would be arranged in a linear chain but structural studies of larger fragments showed them to be more intricate. For example, structure determination of FLNa19-21 and FLN18-19 $[67,82]$ revealed that consecutive domains fold together and have a swapped $\beta$-strand that masks the known binding site for integrin tails $[67,82]$. With colleagues from Finland we recently characterized the module organization of the module sextet FLN16-21 using NMR [130] (Fig. 5). This study was complemented by studies of FLN16-21 by SAXS and of FLN16-24 by cryo-EM [113]. A structural model of the multi-module protein was built using known structures of smaller fragments and RDC restraints obtained for the six-module fragment $[113,130]$.

Fits of the models to the RDCs and ${ }^{15} \mathrm{~N}$ relaxation data strongly implied that there is flexibility within the three-lobed structure of FLNa16-21 [113,130] (Fig. 5(E)). The model also suggested that the known binding sites on modules FLN17, FLN19 and FLN21 are located far enough apart to function independently. It is known that filamin can change its binding properties when force is applied [57] and our model suggests how external forces could open masked binding sites in FLN18-19 and 20-21, a prediction supported by conformational changes we observed when ligands were added to FLN16-21 and FLN16-24 [113]. This filamin study is an example where NMR data - RDCs, chemical shift perturbations and ${ }^{15} \mathrm{~N}$ relaxation rates - gave considerable insight into the functioning of a six-module, $60 \mathrm{kDa}$ protein that could not be crystallized. NMR provided important complementary information to data col- 
A)

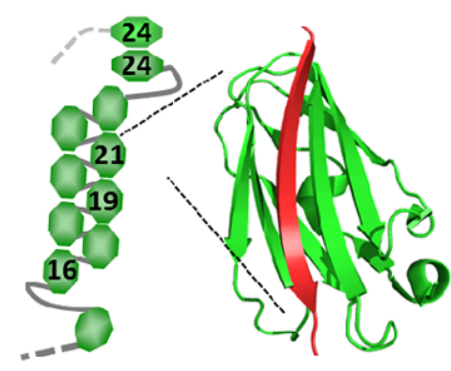

c)

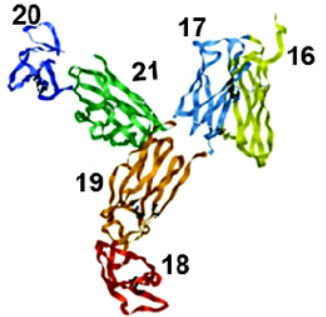

B)

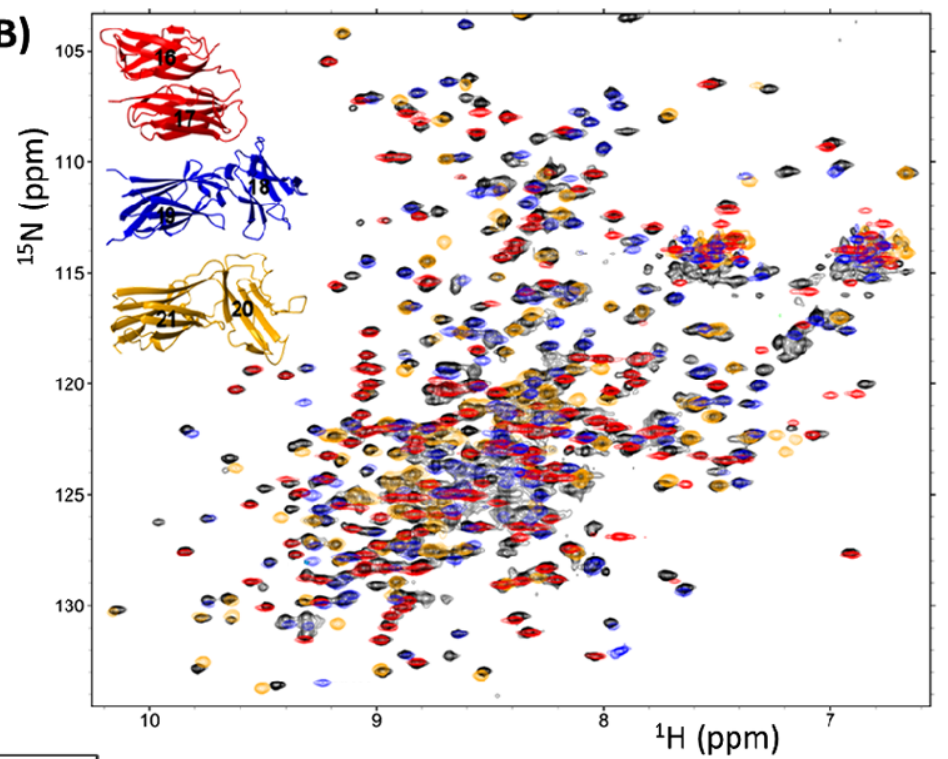

F)
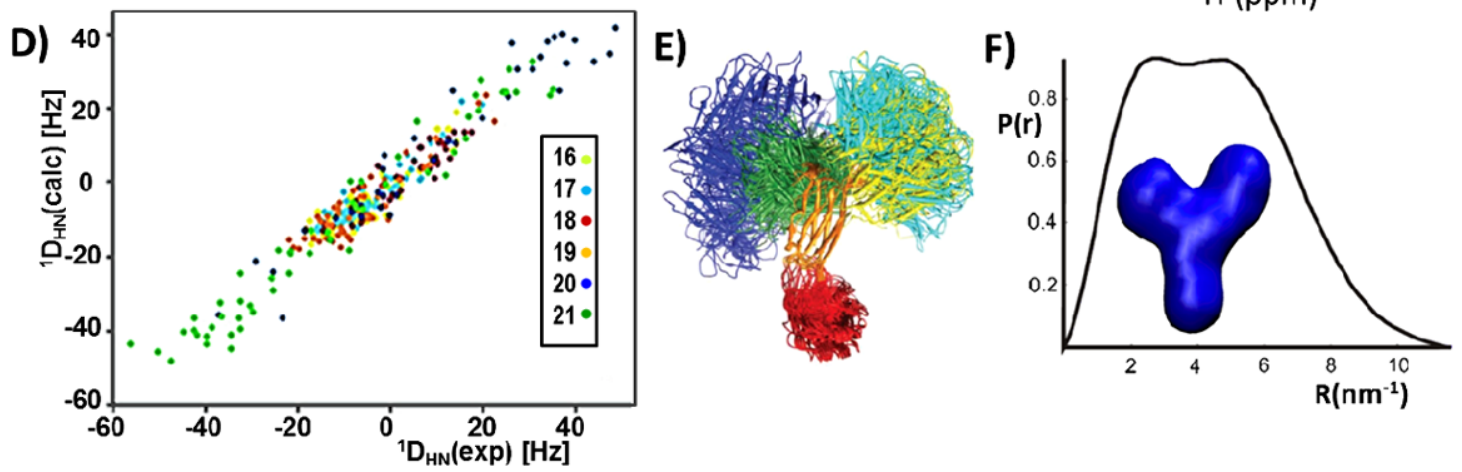

Fig. 5. The multi-domain protein filamin. (A) Filamins are large proteins that link the actin cytoskeleton in cells with membrane-spanning proteins, such as integrins [97]. They consist of a chain of 24 immunoglobulin-like modules (FLN) and an actin binding domain. They form a dimer at the C-terminus via FLN24; FLN15-24 of one chain and FLN24 of the other are illustrated schematically. NMR and crystallography studies have shown that FLN21 binds integrin $\beta$-tails, with the tail (red) inserted as a strand between two strands in the immunoglobulin-like fold of FLN21 (PDB: 2BRQ) [78]. (B) NMR spectra of FLN16-17 (red), FLN18-19 (blue) and FLN20-21 (orange). The structure of each of these domain pairs was determined separately, either by crystallography or NMR [130]. (C) A model of FLN16-21, obtained using RDC restraints and modeling. (D) The correlation between experimental and back-calculated RDCs for the individual domains (the color scheme used for the domains in Fig. 5(C), (D) and (E) is indicated in the inset panel). (E) An ensemble simulation of FLN16-21 showing the ten lowest-energy structures with the FLN19 domains superimposed. (F) The SAXS distance distribution function of FLN16-21 and a corresponding model to fit the data (blue). Panels (B), (C) and (D) are adapted, with permission, from [130] and panel (F) is adapted from [113].

lected on various filamin fragments using other methods, including SAXS, crystallography, cryo-EM and ITC.

\section{Future prospects}

I have emphasized NMR technical improvements in solution state NMR in the last 60 years. It is very unlikely that the next 60 years will see such dramatic changes. Higher fields than the current limit of 
around 23.5 Tesla will no doubt become available but there will be relatively few of these instruments and they will be in National Centers. The cost-effectiveness of very high field instruments is becoming a major consideration. Recent gains in field strength are becoming more and more incremental and expensive (it has been said that it costs $\sim € 6 \mathrm{M}$ extra to go from 900 to $1000 \mathrm{MHz}$ [18]) and the theoretical gains in sensitivity are becoming harder to achieve with currently available probe technology. I see a need for relatively low-cost, easy-to-maintain instruments. Field strengths, up to around 18 Tesla, can be produced without pumping the helium bath, thus lowering cryogenic costs. Scarcity of world helium supplies is a concern and recycling and alternative magnet cooling methods need to be considered. Space requirements can be reduced by 'active shielding' of magnets [127] and there is scope for instrumental compromises; e.g. probes cooled with liquid nitrogen rather than helium. Lower cost, sustainable instruments are more suited to an interdisciplinary era where NMR will not be the entire focus of a project. Instead it will be a tool that is part of an integrated attack directed at understanding protein machinery.

I have focused on solution state studies of proteins, the approach I have been closest to, but I should mention solid state NMR. This method has attracted talented NMR practitioners and there is much current investment in the technology. Spectra can be obtained from 'immobile' samples by employing 'magic angle' spinning and strong decoupling. This is experimentally challenging and the spectral quality obtained is usually poor compared to that from solution state methods but valuable results have been obtained; e.g. the structure of amyloid fibrils and a secretion needle (reviewed in [140]). Membrane proteins represent about $30 \%$ of genomic information and many are effective drug targets, but they are experimentally difficult. Several structures of integral membrane protein structures, with both beta-barrel and polytopic $\alpha$-helix topology, have been solved by NMR [90] and an up-to date list is maintained at http://www.drorlist.com/nmr/MPNMR.html. Solid state NMR was, for many years, believed to be the method of choice for studying membrane proteins but, as can be seen in the list, solution state NMR has been remarkably successful; e.g. the structure determination of seven-helical membrane-spanning proteins $[61,108]$. A wide variety of artificial media that mimic membranes, such as mixed organic solvents, detergents, micelles and bicelles, have been used in NMR studies of membrane proteins. (Finding suitable media is a problem that also applies to crystallography of membrane proteins [94].) Ideally, structural information should be derived from proteins in their native phospholipid bilayer environment. A notable recent structure determination by solid state NMR was of a chemokine receptor; this study ingeniously exploited natural, rapid rotational diffusion of the protein about the bilayer normal [104]. Sample preparation and attainment of near physiological conditions will remain demanding in solid state NMR and, for most membrane proteins, X-ray crystallography will be the structural tool of choice. Solid state NMR is, however, likely to be a useful way of monitoring of protein-ligand interactions $[55,140]$.

Studies of proteins in whole cells have generated some excitement [84,128]. In my view, it remains to be seen whether this technology will produce much valuable information. Fluorescence microscopy, for example, is a much more sensitive way of observing proteins in whole cells than NMR. The NMR spectral quality obtained from whole cell suspensions will often be poor because of magnetic susceptibility and other effects (see Fig. A.1(C)). Important issues like molecular crowding and regulation of reaction rates would probably be better addressed by NMR studies of concentrated cell lysates.

Since its discovery, NMR has moved from an interesting physical phenomenon to an established tool that gives valuable information in diverse areas of research. It is especially powerful in protein studies because of its unique ability to give residue-specific information about structure, dynamics and intermolecular interactions. It can also deal with systems that cannot be crystallized, such and IDPs. These assets are likely to make NMR a much sought after tool for the foreseeable future. 


\section{Acknowledgements}

I am aware that my referencing is biased and incomplete. I apologize to the numerous major contributors to protein NMR studies who are not properly acknowledged here. I owe thanks to many funding agencies for my ability to carry out research. In recent times these include MRC, BBSRC, the Wellcome Trust and NIH. Above all, however, I have been incredibly fortunate to work with numerous illustrious colleagues, collaborators, visitors, outstanding graduate students and post-docs. Most of them are not mentioned here by name but some of their identities can be gleaned from the references given. I thank them and numerous others not referenced at all here for their huge contributions to what has been a very enjoyable research career. I thank Christina Redfield and John Vakonakis for comments on this manuscript.

\section{Appendix. The use of ${ }^{1} \mathrm{H}$ spin echoes to study red cell suspensions}

We carried out $270 \mathrm{MHz}{ }^{1} \mathrm{H}$ studies of red cell suspensions in the 1970s [24,26,28]. I include this here because it illustrates spectral simplification with a simple pulse sequence, the observation of protein signals in whole cells and magnetic susceptibility effects in cell suspensions.
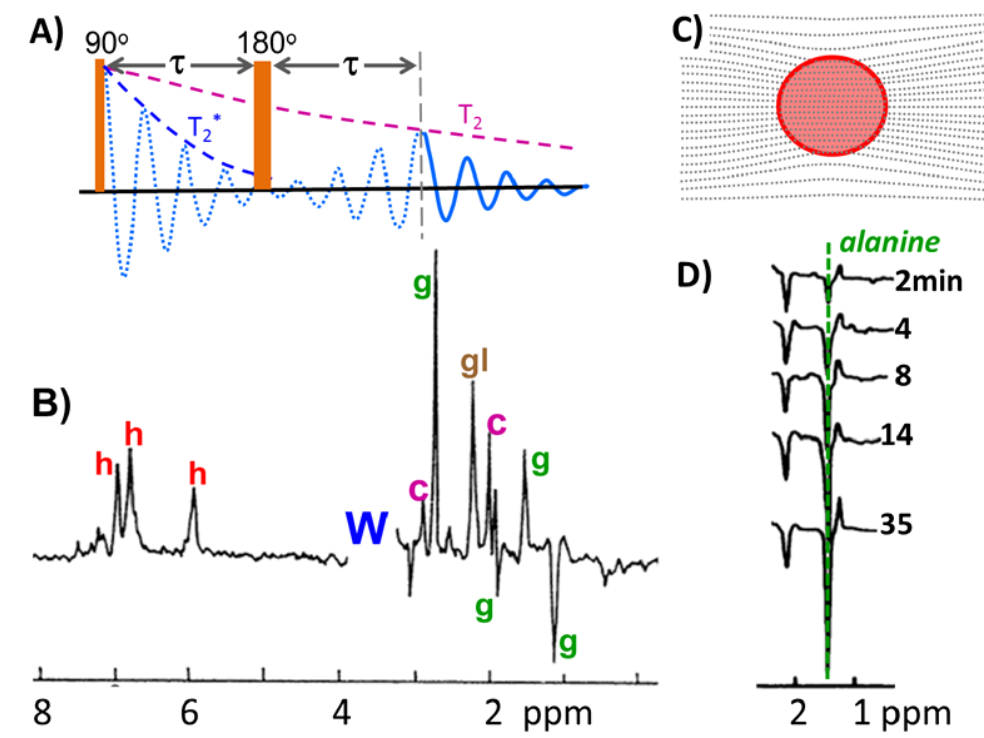

Fig. A.1. ${ }^{1} \mathrm{H}$ spin echo studies of red cells. (A) Simple spin echo sequence showing the $\mathrm{T}_{2}$ decay time as well as $\mathrm{T}_{2}^{*}$. In this configuration, $\mathrm{T}_{2}$ depends on intrinsic transverse relaxation, as well as diffusion through field gradients in the sample while $\mathrm{T}_{2}^{*}$ is dominated by local field inhomogeneities. (B) The spin echo spectrum of red cells obtained at $270 \mathrm{MHz}$, with $\tau=60 \mathrm{~ms}$. The water peak (W) and many other resonances such as those from membranes are greatly attenuated because their effective $\mathrm{T}_{2}$ relaxation rate is fast because of their large size (slow tumbling), exchange effects and radiation damping. The spectrum obtained is dominated by small molecules and histidine residues in hemoglobin which have relatively long $\mathrm{T}_{2}$ values. Some peaks are inverted due to J-modulation effects. Some of the observed peaks are as follows: $\mathrm{h}=$ hemoglobin; $\mathrm{gl}=$ glucose; $\mathrm{g}=$ glutathione; $\mathrm{c}=$ creatine. (C) Cell suspensions show large magnetic susceptibility effects because of intrinsic magnetization differences between different compartments; this illustration of magnetic lines of force suggests that local field inhomogeneities will be larger at the outside cell periphery but this will depend on the nature of the cells and the suspension. (D) A time course of spin echo spectra taken after the addition of alanine to a red cell suspension. The inverted alanine methyl resonance grows as it is transported into the cell where it has a longer effective $T_{2}$ value than when it is outside the cell. Panels (B) and (D) are adapted, with permission, from [26] and [24] respectively. 


\section{References}

[1] A. Allerhand and H.S. Gutowsky, Spin-echo studies of chemical exchange. II. Closed formulas for two sites, Journal of Chemical Physics 42 (1965), 1587-1599.

[2] N.J. Anthis and I.D. Campbell, The tail of integrin activation, Trends in Biochemical Sciences 36 (2011), 191-198.

[3] N.J. Anthis, J.R. Haling, C.L. Oxley, M. Memo, K.L. Wegener, C.J. Lim, M.H. Ginsberg and I.D. Campbell, Beta integrin tyrosine phosphorylation is a conserved mechanism for regulating talin-induced integrin activation, Journal of Biological Chemistry 284 (2009), 36700-36710.

[4] N.J. Anthis, K.L. Wegener, D.R. Critchley and I.D. Campbell, Structural diversity in integrin/talin interactions, Structure 18 (2010), 1654-1666.

[5] N.J. Anthis, K.L. Wegener, F. Ye, C. Kim, B.T. Goult, E.D. Lowe, I. Vakonakis, N. Bate, D.R. Critchley, M.H. Ginsberg and I.D. Campbell, The structure of an integrin/talin complex reveals the basis of inside-out signal transduction, EMBO Journal 28 (2009), 3623-3632.

[6] S. Bader, S. Kuhner and A.C. Gavin, Interaction networks for systems biology, FEBS Letters 582 (2008), 1220-1224.

[7] A.J. Baldwin and L.E. Kay, NMR spectroscopy brings invisible protein states into focus, Nat. Chem. Biol. 5 (2009), $808-814$.

[8] M. Baron, D. Norman, A. Willis and I.D. Campbell, Structure of the fibronectin type 1 module, Nature 345 (1990), 642-646.

[9] M. Baron, D.G. Norman and I.D. Campbell, Protein Modules, Trends in Biochemical Sciences 16 (1991), 13-17.

[10] P.J. Barrett, J. Chen, M.K. Cho, J.H. Kim, Z. Lu, S. Mathew, D. Peng, Y. Song, W.D. Van Horn, T. Zhuang, F.D. Sonnichsen and C.R. Sanders, The quiet renaissance of protein nuclear magnetic resonance, Biochemistry 52 (2013), 1303-1320.

[11] C.D. Barry, A.C. North, J.A. Glasel, R.J. Williams and A.V. Xavier, Quantitative determination of mononucleotide conformations in solution using lanthanide ion shift and broadenine NMR probes, Nature 232 (1971), 236-245.

[12] Q. Bashir, S. Scanu and M. Ubbink, Dynamics in electron transfer protein complexes, FEBS J. 278 (2011), 1391-1400.

[13] A. Bax and A. Grishaev, Weak alignment NMR: a hawk-eyed view of biomolecular structure, Curr. Opin. Struct. Biol. 15 (2005), 563-570.

[14] A. Bax, M. Ikura, L.E. Kay, G. Barbato and S. Spera, Multidimensional triple resonance nmr-spectroscopy of isotopically uniformly enriched proteins - a powerful new strategy for structure determination, Ciba Foundation Symposia 161 (1991), 108-135.

[15] N. Beckmann, New Applications of NMR in Drug Discovery and Development, RSC Publishing, 2013.

[16] A. Bennick, I.D. Campbell, R.A. Dwek, N.C. Price, G.K. Radda and A.G. Salmon, Relationship between conformationally sensitive probe binding sites on phosphorylase b, Nat. New Biol. 234 (1971), 140-143.

[17] W. Bermel, I. Bertini, I.C. Felli and R. Pierattelli, Speeding up (13)C direct detection biomolecular NMR spectroscopy, Journal of the American Chemical Society 131 (2009), 15339-15345.

[18] A. Bhattacharya, Chemistry: Breaking the billion-hertz barrier, Nature 463 (2010), 605-606.

[19] N. Bloembergen and L.O. Morgan, Proton relaxation times in paramagnetic solutions effects of electron spin relaxation, Journal of Chemical Physics 34 (1961), 842-850.

[20] D.D. Boehr, D. McElheny, H.J. Dyson and P.E. Wright, Millisecond timescale fluctuations in dihydrofolate reductase are exquisitely sensitive to the bound ligands, Proc. Natl. Acad. Sci. USA 107 (2010), 1373-1378.

[21] A.M. Bonvin, R. Boelens and R. Kaptein, NMR analysis of protein interactions, Curr. Opin. Chem. Biol. 9 (2005), 501-508.

[22] G.W. Booker, I. Gout, J. Boyd, M.D. Waterfield and I.D. Campbell, Solution structure and ligand-binding site of the SH3 domain of the p85 alpha subunit of phosphatidylinositol 3-kinase, Cell 73 (1993), 813-822.

[23] J. Boyd, N. Soffe and I. Campbell, NMR at very high fields, Structure 2 (1994), 253-255.

[24] K.M. Brindle, F.F. Brown, I.D. Campbell, C. Grathwohl and P.W. Kuchel, Application of spin-echo nuclear magnetic resonance to whole-cell systems. Membrane transport, Biochemical Journal 180 (1979), 37-44.

[25] K.M. Brindle and I.D. Campbell, NMR-studies of kinetics in cells and tissues, Quarterly Reviews of Biophysics 19 (1987), 159-182.

[26] F.F. Brown and I.D. Campbell, NMR studies of red cells, Philos. Trans. R. Soc. Lond. B - Biol. Sci. 289 (1980), $395-406$.

[27] F.F. Brown, I.D. Campbell, R. Henson, C.W.J. Hirst and R.E. Richards, Study of interaction of manganese ions with Atp by P-31 Fourier-transform nuclear-magnetic resonance, European Journal of Biochemistry 38 (1973), 54-58.

[28] F.F. Brown, I.D. Campbell, P.W. Kuchel and D.C. Rabenstein, Human erythrocyte metabolism studies by H-1 Spin-Echo NMR, FEBS Letters 82 (1977), 12-16.

[29] M.F. Brown and S.I. Chan, Bilayer Membranes: Deuterium and Carbon-13 NMR, Wiley, 2007.

[30] D.A. Calderwood, I.D. Campbell and D.R. Critchley, Talins and kindlins: partners in integrin-mediated adhesion, Nat. Rev. Mol. Cell. Biol. 14 (2013), 503-517.

[31] I.D. Campbell, The Croonian lecture 2006 Structure of the living cell, Philosophical Transactions of the Royal Society B - Biological Sciences 363 (2008), 2379-2391. 
[32] I.D. Campbell, Studies of focal adhesion assembly, Biochem. Soc. Trans. 36 (2008), 263-266.

[33] I.D. Campbell, Biophysical Techniques, Oxford Univ. Press, Oxford, 2012.

[34] I.D. Campbell, J.P. Carver, R.A. Dwek, A.J. Nummelin and R.E. Richards, Proton relaxation of methyl cyanide in the presence of Ni(II) ions as studied by spin echo techniques, Molecular Physics 20 (1971), 913-922.

[35] I.D. Campbell, C.M. Dobson, G.R. Moore, S.J. Perkins and R.J. Williams, Temperature dependent molecular motion of a tyrosine residue of ferrocytochrome C, FEBS Letters 70 (1976), 96-100.

[36] I.D. Campbell, C.M. Dobson and R.J.P. Williams, Nuclear magnetic-resonance studies on structure of lysozyme in solution, Proceedings of the Royal Society of London Series A - Mathematical Physical and Engineering Sciences 345 (1975), 41-59.

[37] I.D. Campbell, C.M. Dobson, R.J.P. Williams and P.E. Wright, Pulse methods for simplification of protein NMR-spectra, FEBS Letters 57 (1975), 96-99.

[38] I.D. Campbell, C.M. Dobson, R.J.P. Williams and A.V. Xavier, Resolution enhancement of protein PMR spectra using difference between a broadened and a normal spectrum, Journal of Magnetic Resonance 11 (1973), 172-181.

[39] I.D. Campbell, R.A. Dwek, N.C. Price and G.K. Radda, Studies on the interaction of ligands with phosphorylase b using a spin-label probe, European Journal of Biochemistry 30 (1972), 339-347.

[40] I.D. Campbell and R. Freeman, Determination of nuclear overhauser enhancement factors from NMR spin-lattice relaxation rates, Journal of Chemical Physics 58 (1973), 2666-2667.

[41] I.D. Campbell and M.J. Humphries, Integrin structure, activation, and interactions, Cold Spring Harb. Perspect. Biol. 3 (2011), 169-182.

[42] J. Cavanagh, W.J. Fairbrother, A.G. Palmer, M. Rance and N.J. Skelton, Protein NMR Spectroscopy Principles and Practice, 2nd edn, 2007.

[43] K. Chen and N. Tjandra, The use of residual dipolar coupling in studying proteins by NMR, Topics in Current Chemistry 326 (2012), 47-67.

[44] T.D.W. Claridge, High-Resolution NMR Techniques in Organic Chemistry, Pergamon, 2000.

[45] G.M. Clore, P.C. Driscoll, P.T. Wingfield and A.M. Gronenborn, Analysis of the backbone dynamics of interleukin-1 beta using two-dimensional inverse detected heteronuclear 15N-1H NMR spectroscopy, Biochemistry 29 (1990), 7387-7401.

[46] G.M. Clore and J. Iwahara, Theory, practice, and applications of paramagnetic relaxation enhancement for the characterization of transient low-population states of biological macromolecules and their complexes, Chemical Reviews 109 (2009), 4108-4139.

[47] G.R. Coates, L. Xiao and M.G. Prammer, NMR Logging Principles and Applications, Haliburton, 1999.

[48] H.B. Coates, K.A. McLaughlan, I.D. Campbell and C.E. McColl, Proton spin lattice relaxation time measurements at $90 \mathrm{MHz}$ and $270 \mathrm{MHz}$, Biochimica Et Biophysica Acta 310 (1973), 1-10.

[49] S.A. Combs, S.L. Deluca, S.H. Deluca, G.H. Lemmon, D.P. Nannemann, E.D. Nguyen, J.R. Willis, J.H. Sheehan and J. Meiler, Small-molecule ligand docking into comparative models with Rosetta, Nat. Protoc. 8 (2013), 1277-1298.

[50] R.M. Cooke, A.J. Wilkinson, M. Baron, A. Pastore, M.J. Tappin, I.D. Campbell, H. Gregory and B. Sheard, The solution structure of human epidermal growth factor, Nature 327 (1987), 339-341.

[51] G.M. Daubner, A. Clery and F.H. Allain, RRM-RNA recognition: NMR or crystallography ... and new findings, Curr. Opin. Struct. Biol. 23 (2013), 100-108.

[52] R.A. de Graaf, In Vivo NMR Spectroscopy - Principles and Techniques, Wiley, 2013.

[53] J.M. de Pereda, K.L. Wegener, E. Santelli, N. Bate, M.H. Ginsberg, D.R. Critchley, I.D. Campbell and R.C. Liddington, Structural basis for phosphatidylinositol phosphate kinase type I gamma binding to talin at focal adhesions, Journal of Biological Chemistry 280 (2005), 8381-8386.

[54] A. Dehner and H. Kessler, Diffusion NMR spectroscopy: folding and aggregation of domains in p53, ChemBioChem. 6 (2005), 1550-1565.

[55] X. Ding, X. Zhao and A. Watts, G-protein-coupled receptor structure, ligand binding and activation as studied by solidstate NMR spectroscopy, Biochemical Journal 450 (2013), 443-457.

[56] S.B. Duckett and R.E. Mewis, Improving NMR and MRI sensitivity with parahydrogen, Topics in Current Chemistry 338 (2013), 75-104.

[57] A.J. Ehrlicher, F. Nakamura, J.H. Hartwig, D.A. Weitz and T.P. Stossel, Mechanical strain in actin networks regulates FilGAP and integrin binding to filamin A, Nature 478 (2011), 260-263.

[58] R.R. Ernst and W.A. Anderson, Application of Fourier transform spectroscopy to magnetic resonance, Review of Scientific Instruments 37 (1966), 93-102.

[59] D.P. Frueh, A.C. Goodrich, S.H. Mishra and S.R. Nichols, NMR methods for structural studies of large monomeric and multimeric proteins, Curr. Opin. Struct. Biol. (2013).

[60] B. Garcia-Alvarez, J.M. de Pereda, D.A. Calderwood, T.S. Ulmer, D. Critchley, I.D. Campbell, M.H. Ginsberg and R.C. Liddington, Structural determinants of integrin recognition by talin, Molecular Cell 11 (2003), 49-58. 
[61] A. Gautier, H.R. Mott, M.J. Bostock, J.P. Kirkpatrick and D. Nietlispach, Structure determination of the seven-helix transmembrane receptor sensory rhodopsin II by solution NMR spectroscopy, Nature Structural \& Molecular Biology 17 (2010), 768-774.

[62] W. Gronwald and H.R. Kalbitzer, Automated protein NMR structure determination in solution, Methods in Molecular Biology 673 (2010), 95-127.

[63] P. Guntert, Automated structure determination from NMR spectra, Eur. Biophys. J. 38 (2009), 129-143.

[64] H.S. Gutowsky, D.W. McCall and C.P. Slichter, Nuclear magnetic resonance multiplets in liquids, Journal of Chemical Physics 21 (1953), 279-292.

[65] P.A. Handford, M. Mayhew, M. Baron, P.R. Winship, I.D. Campbell and G.G. Brownlee, Key residues involved in calcium-binding motifs in egf-like domains, Nature 351 (1991), 164-167.

[66] T.F. Havel and K. Wuthrich, An evaluation of the combined use of nuclear magnetic resonance and distance geometry for the determination of protein conformations in solution, Journal of Molecular Biology 182 (1985), 281-294.

[67] O.K. Heikkinen, S. Ruskamo, P.V. Konarev, D.I. Svergun, T. Iivanainen, S.M. Heikkinen, P. Permi, H. Koskela, I. Kilpelainen and J. Ylanne, Atomic structures of two novel immunoglobulin-like domain pairs in the actin cross-linking protein filamin, Journal of Biological Chemistry 284 (2009), 25450-25458.

[68] D.I. Hoult, S.J. Busby, D.G. Gadian, G.K. Radda, R.E. Richards and P.J. Seeley, Observation of tissue metabolites using 31P nuclear magnetic resonance, Nature 252 (1974), 285-287.

[69] D.I. Hoult and R.E. Richards, Signal-to-noise ratio of nuclear magnetic-resonance experiment, Journal of Magnetic Resonance 24 (1976), 71-85.

[70] S.G. Hyberts, S.A. Robson and G. Wagner, Exploring signal-to-noise ratio and sensitivity in non-uniformly sampled multi-dimensional NMR spectra, Journal of Biomolecular NMR 55 (2013), 167-178.

[71] M.R. Jensen, R.W. Ruigrok and M. Blackledge, Describing intrinsically disordered proteins at atomic resolution by NMR, Curr. Opin. Struct. Biol. 23 (2013), 426-435.

[72] M. Kainosho and P. Guntert, SAIL-stereo-array isotope labeling, Quarterly Reviews of Biophysics 42 (2009), 247-300.

[73] A.C. Kalli, I.D. Campbell and M.S.P. Sansom, Multiscale simulations suggest a mechanism for integrin inside-out activation, Proceedings of the National Academy of Sciences of the United States of America 108 (2011), 11890-11895.

[74] E. Karaca and A.M. Bonvin, Advances in integrative modeling of biomolecular complexes, Methods 59 (2013), 372-381.

[75] L.E. Kay, D.A. Torchia and A. Bax, Backbone dynamics of proteins as studied by $15 \mathrm{~N}$ inverse detected heteronuclear NMR spectroscopy: application to staphylococcal nuclease, Biochemistry 28 (1989), 8972-8979.

[76] P.H. Keizers and M. Ubbink, Paramagnetic tagging for protein structure and dynamics analysis, Prog. Nucl. Magn. Reson. Spectrosc. 58 (2011), 88-96.

[77] J.C. Kendrew, G. Bodo, H.M. Dintzis, R.G. Parrish, H. Wyckoff and D.C. Phillips, A three-dimensional model of the myoglobin molecule obtained by x-ray analysis, Nature 181 (1958), 662-666.

[78] T. Kiema, Y. Lad, P.J. Jiang, C.L. Oxley, M. Baldassarre, K.L. Wegener, I.D. Campbell, J. Ylanne and D.A. Calderwood, The molecular basis of filamin binding to integrins and competition with talin, Molecular Cell 21 (2006), 337-347.

[79] E.L. Kovrigin, NMR line shapes and multi-state binding equilibria, Journal of Biomolecular NMR 53 (2012), $257-270$.

[80] A. Kumar, R.R. Ernst and K. Wuthrich, A two-dimensional nuclear overhauser enhancement (2d Noe) experiment for the elucidation of complete proton-proton cross-relaxation networks in biological macromolecules, Biochemical and Biophysical Research Communications 95 (1980), 1-6.

[81] Y. Lad, P. Jiang, S. Ruskamo, D.S. Harburger, J. Ylanne, I.D. Campbell and D.A. Calderwood, Structural basis of the migfilin-filamin interaction and competition with integrin beta tails, Journal of Biological Chemistry 283 (2008), 35154-35163.

[82] Y. Lad, T. Kiema, P.J. Jiang, O.T. Pentikainen, C.H. Coles, I.D. Campbell, D.A. Calderwood and J. Ylaenne, Structure of three tandem filamin domains reveals auto-inhibition of ligand binding, EMBO Journal 26 (2007), 3993-4004.

[83] K.W. Lexa and H.A. Carlson, Protein flexibility in docking and surface mapping, Quarterly Reviews of Biophysics 45 (2012), 301-343.

[84] C. Li and M. Liu, Protein dynamics in living cells studied by in-cell NMR spectroscopy, Febs Letters 587 (2013), $1008-1011$.

[85] J.C. Lindon and E. Holmes, NMR Spectroscopy of Biofluids, Tissues, and Tissue Extracts, Wiley, 2013.

[86] A.L. Main, T.S. Harvey, M. Baron, J. Boyd and I.D. Campbell, The 3-dimensional structure of the 10th type-III module of fibronectin - an insight into Rgd-mediated interactions, Cell 71 (1992), 671-678.

[87] T.K. Mal, S.J. Matthews, H. Kovacs, I.D. Campbell and J. Boyd, Some NMR experiments and a structure determination employing a $[15 \mathrm{~N}, 2 \mathrm{H}]$ enriched protein, Journal of Biomolecular NMR 12 (1998), 259-276.

[88] T. Maly, G.T. Debelouchina, V.S. Bajaj, K.N. Hu, C.G. Joo, M.L. Mak-Jurkauskas, J.R. Sirigiri, P.C. van der Wel, J. Herzfeld, R.J. Temkin and R.G. Griffin, Dynamic nuclear polarization at high magnetic fields, Journal of Chemical Physics 128 (2008), 052211.

[89] S. Marqusee and R.L. Baldwin, Helix stabilization by Glu-... Lys + salt bridges in short peptides of de novo design, Proc. Natl. Acad. Sci. USA 84 (1987), 8898-8902. 
[90] I. Maslennikov and S. Choe, Advances in NMR structures of integral membrane proteins, Curr. Opin. Struct. Biol. 23 (2013), 555-562.

[91] C.C. Mcdonald and W.D. Phillips, Manifestations of tertiary structures of proteins in high-frequency nuclear magnetic resonance, Journal of the American Chemical Society 89 (1967), 6332-6341.

[92] A.C. McLaughlin, P.R. Cullis, M.A. Hemminga, D.I. Hoult, G.K. Radda, G.A. Ritchie, P.J. Seeley and R.E. Richards, Application of 31P NMR to model and biological membrane systems, FEBS Letters 57 (1975), 213-218.

[93] D.H. Meadows, O. Jardetzky, R.M. Epand, H.H. Ruterjans and H.A. Scheraga, Assignment of the histidine peaks in the nuclear magnetic resonance spectrum of ribonuclease, Proc. Natl. Acad. Sci. USA 60 (1968), 766-772.

[94] I. Moraes, G. Evans, J. Sanchez-Weatherby, S. Newstead and P.D. Stewart, Membrane protein structure determination The next generation, Biochimica et Biophysica Acta (2013).

[95] V. Munoz and L. Serrano, Development of the multiple sequence approximation within the AGADIR model of alphahelix formation: comparison with Zimm-Bragg and Lifson-Roig formalisms, Biopolymers 41 (1997), 495-509.

[96] K. Nagayama, K. Wuthrich, P. Bachmann and R.R. Ernst, Two-dimensional J-resolved 1H NMR spectroscopy for studies of biological macromolecules, Biochem. Biophys. Res. Commun. 78 (1977), 99-105.

[97] F. Nakamura, T.M. Osborn, C.A. Hartemink, J.H. Hartwig and T.P. Stossel, Structural basis of filamin A functions, J. Cell. Biol. 179 (2007), 1011-1025.

[98] T.J. Norwood, J. Boyd, J.E. Heritage, N. Soffe and I.D. Campbell, Comparison of techniques for H-1-detected heteronuclear H-1-N-15 spectroscopy, Journal of Magnetic Resonance 87 (1990), 488-501.

[99] M.R. O'Connell, R. Gamsjaeger and J.P. Mackay, The structural analysis of protein-protein interactions by NMR spectroscopy, Proteomics 9 (2009), 5224-5232.

[100] I. Oliveira, R. Sarthour, Jr., T. Bonagamba, E. Azevedo and J.C.C. Freitas, NMR Quantum Information Processing Ebook, Elsevier, 2011.

[101] M. Osawa, K. Takeuchi, T. Ueda, N. Nishida and I. Shimada, Functional dynamics of proteins revealed by solution NMR, Curr. Opin. Struct. Biol. 22 (2012), 660-669.

[102] H. Oschkinat, C. Griesinger, P.J. Kraulis, O.W. Sorensen, R.R. Ernst, A.M. Gronenborn and G.M. Clore, Threedimensional NMR spectroscopy of a protein in solution, Nature 332 (1988), 374-376.

[103] G. Otting, Protein NMR using paramagnetic ions, Annu. Rev. Biophys. 39 (2010), 387-405.

[104] S.H. Park, B.B. Das, F. Casagrande, Y. Tian, H.J. Nothnagel, M. Chu, H. Kiefer, K. Maier, A.A. De Angelis, F.M. Marassi and S.J. Opella, Structure of the chemokine receptor CXCR1 in phospholipid bilayers, Nature 491 (2012), 779-783.

[105] M. Pellecchia, I. Bertini, D. Cowburn, C. Dalvit, E. Giralt, W. Jahnke, T.L. James, S.W. Homans, H. Kessler, C. Luchinat, B. Meyer, H. Oschkinat, J. Peng, H. Schwalbe and G. Siegal, Perspectives on NMR in drug discovery: a technique comes of age, Nat. Rev. Drug Discov. 7 (2008), 738-745.

[106] A.R. Pickford and I.D. Campbell, NMR studies of modular protein structures and their interactions, Chemical Reviews 104 (2004), 3557-3565.

[107] R.A. Poldrack, J.A. Mumford and T.E. Nichols, Handbook of Functional MRI Data Analysis, Cambridge Univ. Press, 2011.

[108] S. Reckel, D. Gottstein, J. Stehle, F. Lohr, M.K. Verhoefen, M. Takeda, R. Silvers, M. Kainosho, C. Glaubitz, J. Wachtveitl, F. Bernhard, H. Schwalbe, P. Guntert and V. Dotsch, Solution NMR structure of proteorhodopsin, Angew. Chem. Int. Ed. Engl. 50 (2011), 11942-11946.

[109] C. Redfield, NMR studies of partially folded molten-globule states, Methods in Molecular Biology 278 (2004), $233-254$.

[110] E. Rennella and B. Brutscher, Fast real-time NMR methods for characterizing short-lived molecular states, ChemPhysChem 14 (2013), 3059-3070.

[111] R.E. Richards and J.A.S. Smith, NMR of some acid hydrates, Transactions of the Faraday Society 47 (1951), 1261-1274.

[112] A.M. Ruschak and L.E. Kay, Methyl groups as probes of supra-molecular structure, dynamics and function, Journal of Biomolecular NMR 46 (2010), 75-87.

[113] S. Ruskamo, R. Gilbert, G. Hofmann, P. Jiang, I.D. Campbell, J. Ylanne and U. Pentikainen, The C-terminal rod 2 fragment of filamin A forms a compact structure that can be extended, Biochemical Journal 446 (2012), 261-269.

[114] M. Saunders, A. Wishnia and J.G. Kirkwood, The nuclear magnetic resonance spectrum of ribonuclease, Journal of the American Chemical Society 79 (1957), 3289-3290.

[115] A. Sekhar and L.E. Kay, NMR paves the way for atomic level descriptions of sparsely populated, transiently formed biomolecular conformers, Proc. Natl. Acad. Sci. USA (2013).

[116] S.J. Shattil, C. Kim and M.H. Ginsberg, The final steps of integrin activation: the end game, Nat. Rev. Mol. Cell. Biol. 11 (2010), 288-300.

[117] Y. Shen and A. Bax, Protein backbone and sidechain torsion angles predicted from NMR chemical shifts using artificial neural networks, Journal of Biomolecular NMR 56 (2013), 227-241.

[118] Y. Shen, O. Lange, F. Delaglio, P. Rossi, J.M. Aramini, G. Liu, A. Eletsky, Y. Wu, K.K. Singarapu, A. Lemak, A. Ignatchenko, C.H. Arrowsmith, T. Szyperski, G.T. Montelione, D. Baker and A. Bax, Consistent blind protein structure generation from NMR chemical shift data, Proc. Natl. Acad. Sci. USA 105 (2008), 4685-4690. 
[119] L.J. Smith, A.M. Bowen, A. Di Paolo, A. Matagne and C. Redfield, The dynamics of lysozyme from bacteriophage lambda in solution probed by NMR and MD simulations, ChemBioChem (2013).

[120] R. Sprangers and L.E. Kay, Quantitative dynamics and binding studies of the 20S proteasome by NMR, Nature 445 (2007), 618-622.

[121] A. Spyros and P. Dais, NMR Spectroscopy in Food Analysis, RSC Publishing, 2013.

[122] D. Staunton, C.J. Millard, A.R. Aricescu and I.D. Campbell, Preparation of recombinant fibronectin fragments for functional and structural studies, Methods in Molecular Biology 522 (2009), 73-99.

[123] D. Staunton, R. Schlinkert, G. Zanetti, S.A. Colebrook and I.D. Campbell, Cell-free expression and selective isotope labelling in protein NMR, Magn. Reson. Chem. 44(Spec No) (2006), S2-S9.

[124] R. Štefl and V. Sklenáŕ, RNA, Wiley, 2012.

[125] P. Styles, N.F. Soffe, C.A. Scott, D.A. Cragg, F. Row, D.J. White and P.C.J. White, A high-resolution NMR probe in which the coil and preamplifier are cooled with liquid-helium, Journal of Magnetic Resonance 60 (1984), 397-404.

[126] H. Takahashi and I. Shimada, Production of isotopically labeled heterologous proteins in non-E. coli prokaryotic and eukaryotic cells, Journal of Biomolecular NMR 46 (2010), 3-10.

[127] R. Teodorescu, J. Colvin, G. Shotzman, T. Vick, J. Zeigler, G. Liang, L. Crowe, C. Abshire, T. Mann, Z. Parakh and W. Shen, $400 \mathrm{MHz} / 89 \mathrm{~mm}$ actively shielded high resolution NMR magnet, IEEE Transactions on Magnetics 32 (1996), 2647-2650.

[128] H. Tochio, Watching protein structure at work in living cells using NMR spectroscopy, Curr. Opin. Chem. Biol. 16 (2012), 609-613.

[129] P. Tompa, Intrinsically disordered proteins: a 10-year recap, Trends in Biochemical Sciences 37 (2012), 509-516.

[130] H. Tossavainen, O. Koskela, P.J. Jiang, J. Ylanne, I.D. Campbell, I. Kilpelainen and P. Permi, Model of a six immunoglobulin-like domain fragment of filamin A (16-21) built using residual dipolar couplings, Journal of the American Chemical Society 134 (2012), 6660-6672.

[131] V. Tugarinov, P.M. Hwang, J.E. Ollerenshaw and L.E. Kay, Cross-correlated relaxation enhanced 1H-13C NMR spectroscopy of methyl groups in very high molecular weight proteins and protein complexes, Journal of the American Chemical Society 125 (2003), 10420-10428.

[132] M. Tyagi, K. Hashimoto, B.A. Shoemaker, S. Wuchty and A.R. Panchenko, Large-scale mapping of human protein interactome using structural complexes, EMBO Rep. 13 (2012), 266-271.

[133] S.R. Tzeng, M.T. Pai and C.G. Kalodimos, NMR studies of large protein systems, Methods in Molecular Biology 831 (2012), 133-140.

[134] T.S. Ulmer, Structural basis of transmembrane domain interactions in integrin signaling, Cell Adh. Migr. 4 (2010), $243-248$.

[135] T.S. Ulmer, B. Yaspan, M.H. Ginsberg and I.D. Campbell, NMR analysis of structure and dynamics of the cytosolic tails of integrin alpha IIb beta 3 in aqueous solution, Biochemistry 40 (2001), 7498-7508.

[136] V.N. Uversky, The most important thing is the tail: Multitudinous functionalities of intrinsically disordered protein termini, FEBS Letters 587 (2013), 1891-1901.

[137] J.F.G. Vliegenthart and R.J. Woods, NMR Spectroscopy and Computer Modeling of Carbohydrates: Recent Advances, American Chemical Society, 2006.

[138] A.J. Wand, H. Roder and S.W. Englander, Two-dimensional 1H NMR studies of cytochrome c: hydrogen exchange in the N-terminal helix, Biochemistry 25 (1986), 1107-1114.

[139] K.L. Wegener, A.W. Partridge, J. Han, A.R. Pickford, R.C. Liddington, M.H. Ginsberg and I.D. Campbell, Structural basis of integrin activation by talin, Cell 128 (2007), 171-182.

[140] M. Weingarth and M. Baldus, Solid-state NMR-based approaches for supramolecular structure elucidation, Acc. Chem. Res. 46 (2013), 2037-2046.

[141] C. Westbrook, C.K. Roth and J. Talbot, MRI in Practice, Wiley-Blackwell, 2011.

[142] M.P. Williamson, T.F. Havel and K. Wuthrich, Solution conformation of proteinase inhibitor IIA from bull seminal plasma by $1 \mathrm{H}$ nuclear magnetic resonance and distance geometry, Journal of Molecular Biology 182 (1985), $295-315$.

[143] P.E. Wright and H.J. Dyson, Linking folding and binding, Curr. Opin. Struct. Biol. 19 (2009), 31-38.

[144] K. Wuthrich, Nuclear Magnetic Resonance of Proteins and Nucleic Acids, Wiley, 1986.

[145] K. Wuthrich, G. Wider, G. Wagner and W. Braun, Sequential resonance assignments as a basis for determination of spatial protein structures by high resolution proton nuclear magnetic resonance, Journal of Molecular Biology 155 (1982), 311-319.

[146] F. Ye, C. Kim and M.H. Ginsberg, Reconstruction of integrin activation, Blood 119 (2012), 26-33. 